\title{
AC 2007-2999: EXPANDING GIRLS' HORIZONS IN MATH AND SCIENCE: A LONGITUDINAL EVALUATION OF EYH CONFERENCE OUTCOMES
}

\section{Mary Virnoche, Humboldt State University}

Mary is an associate professor of Sociology at Humboldt State University. Since graduate school she has been committed to community-based research and applied work with a focus on race, class and gender inequities. While a gradaute student and then a research associate at the University of Colorado, she facilitated partnerships between STEM professionals, educators and marginalized communities in addressing digital divide concerns. Since joining the faculty at HSU, Mary has focused on facilitating the participation of girls in the STEM pipeline and workforce. She is currently working on research on girls' career and course taking decisions. In addition, she is the evaluator and a collaborator (co-PI) on an NSF Scientific Leadership Scholars grant funding American Indian and first generation college students who study Computer Science, Environmnetal Resource Engineering or Math at HSU.

\section{Elizabeth Eschenbach, Humboldt State University}

Beth Eschenbach is a professor of Environmental Resources Engineering at Humboldt State University. Beth left civil engineering as an undergraduate at UC Santa Cruz, and graduated with honors in mathematics and in psychology. She obtained her MS and PhD at Cornell in Environmental and Water Resources Systems Engineering. She completed a postdoc at the Center for Advanced Decision Support in Water and Environmental Systems (CADSWES) at UC Boulder. Beth's career goals include increasing the diversity of engineering students and improving education for all engineering students. Three of Beth's current projects are: 1) an NSF planning project for the Collaborative Large-scale Engineering Analysis Network for Environmental Research, 2) an NSF Scientific Leadership Scholars project providing 4-year scholarships to 30 students in computer science, environmental recourses engineering and mathematics and 3) a water resources curriculum project using CADSWES software. 


\title{
Expanding Girls' Horizons in Math and Science: A Longitudinal Evaluation of EYH Conference Outcomes
}

\begin{abstract}
Little longitudinal data is available on the effectiveness of Expanding Your Horizons conferences on impacting girls' future decisions regarding math and science. The purpose of the conferences is to encourage girls to take more math and science in high school by exposing them to hands-on activities and role models in the areas of science, technology, engineering and mathematics (STEM). This paper is based on interview data from 22 high school girls who between 2005 and 2006 participated in one-to-one interviews and small group discussions. These 22 girls as middle school students had all participated in an Expanding Your Horizons Conference at Humboldt State University. Themes and patterns across interview data emerged through the application of qualitative data analysis techniques and specialized software (NVivo). We specifically consider Native American and Caucasian girls' memories of EYH and their perceptions of how participation in EYH influenced their high school course taking and career anticipation. While a few of the girls could not recall the EYH experience, most of the girls relayed detailed descriptions of their day. Some of these girls then drew connections between the EYH conference, their course taking actions and career goals. Results indicate that some girls take math and science in high school so they can attend college, but they have no intention of majoring in a STEM area. Suggestions for more effective EYH conferences include: 1) partner with engaged teachers and counselors of students with less college savvy parents to help these girls attend. 2) Workshop leaders must understand that workshops need to be hands-on and not "just like school" 3) If possible, provide girls opportunities to identify with women that "have it all" (beauty, popularity, intelligence and accomplishment). 4) Workshop leaders should be sure to explain their career paths, as girls are only exposed to the career paths they find in popular media. 5) Workshop leaders need to show multiple perspectives and solutions to problems and experimental design, as some girls find math and science unattractive because they think those types of problems only have one solution. 6) It is important to have multiple interventions over a girls' teenage years as the positive impact of the EYH fades over time. 7) Role models and parents have lots of influence. Those schools need to hire female math and science instructors and teachers and parents need workshops to help them envision a broader future for their girls.
\end{abstract}

Keywords: Gender, Math, Science, Course Selection, Career Decisions, Evaluation

\section{Introduction}

Even though girls perform as well as boys in science and math, there is a marked loss in interest in STEM (Science Technology Engineering and Mathematics) areas that occurs in middle school $1,2,3,4$. Research has shown that middle school girls' attitudes about careers and math and science affect young women's persistence and involvement in advanced coursework during their high school years ${ }^{5}$. This finding suggests that there is a need for intervention at the middle school level or earlier. There are many possible causes for this change in interest. Different expectations for girls and boys can lead to gender bias in the classroom ${ }^{6,7,8,9,10}$. Inadequate 
representation of strong female role models in STEM fields has also been documented as a barrier to girls' interest and participation ${ }^{11}$.

Female students, and students of color in general, are more likely to report that math and science education is often devoid of application to solving community problems and problematic for them on multiple levels ${ }^{12}$. So while much of the gender gap in high school math and science course taking has been closed, these high school enrollment practices have not translated into STEM higher education and career paths for girls ${ }^{13}$. Girls have shifted from a "we can't do it" paradigm to a "we can, but I don't want to" orientation ${ }^{14}$.

In this study, we ask "how do high school girls who attended an Expanding Your Horizon's $(\mathrm{EYH})$ conference at Humboldt State University make decisions about course taking and career planning"? We specifically consider Native American and Caucasian girls' memories of EYH and their perceptions of how participation in EYH influenced their high school course taking and career anticipation. This paper reports results from semistructured interviews of 22 high school of the approximately 100 girls identified who participated in a 2001 or 2003 Humboldt State University Expanding Your Horizons Conference while in middle school. The narratives of this sample of girls offer insights into the range of experiences and longitudinal outcomes of 2001 and 2003 Humboldt State University EYH participants.

\section{Expanding Your Horizons Background}

The EYH Network, formerly known as the Math/Science Network, was started in 1974 by a group of women scientists and educators to address the issues of women's low participation in math courses. Since EYH's inception, more than 600,000 girls and more than 60,000 parents and educators have participated at conferences around the nation. The purpose of the conference is to encourage girls to take more math and science in high school by exposing them to hands-on activities and role models in the areas of science, technology, engineering and mathematics. In 2004 there were 81 registered conference sites serving more than 24,000 girls, $41 \%$ of the girls identified as ethnic minority members. More than 3500 adults also participated. These conferences relied on the work of almost 5000 volunteers including planning committee members and presenters ${ }^{15}$.

The Humboldt State University Expanding Your Horizons Conference has been held biennially since 1986. Each conference about 350 girls and 100 adults participate. More than 200 volunteers put on the conference. The Humboldt EYH conference serves a lowersocioeconomic, rural community that has one of the largest Native American populations in California ${ }^{16}$. The majority of the girls who have attended the EYH conferences at Humboldt come from Humboldt and Trinity Counties in Northern California. Both of these counties are rural communities approximately 6 driving hours north of San Francisco. The geographic location cuts off both of these counties from many of the resources and opportunities found in other communities that are more connected to urban areas of California. The local conference is sponsored by Humboldt State University, the American Association of University Women Humboldt Branch and other area organizations and businesses. 


\section{Existing Longitudinal Evaluation Research On EYH}

The EYH Network asks conference organizers to collect and report on attendee demographics and attitudinal data regarding workshops, speakers and conference organization. These evaluations are overwhelming positive $e^{16,18,19}$. Yet immediate evaluations as described above offer little insight into lasting influences of EYH. Like many programs designed to effect social change, there has been little longitudinal data collected on long-term program-related outcomes. According to the EYH Network, there have been three longitudinal evaluations of EYH conferences to date, including a national survey initiated in 2002 by the EYH Network office.

The EYH Network in 2002 conducted the most recent of the three longitudinal studies. The EYH Network partnered with the Center for History and Media Echo Project at George Mason University to collect national data on EYH alumnae ${ }^{20}$. As of January 2006, 54 participants had been solicited through announcements and networking via professional organizations. Along with demographic and contact information, the survey solicited data on a combination of seven closed and open-ended questions regarding participation in EYH, education and career experiences.

Most (81\%) had positive or very positive reactions to EYH. Most $(87 \%)$ had math or science related majors in college. Almost half (48\%) reported moderate to strong influence of EYH on their undergraduate major. Along with EYH, participants also discussed the influence of teachers or other unrelated mentors and parents or other family members ${ }^{16}$.

While the results are positive, they must be considered with caution. First, recruitment of respondents was heaviest in science organizations. So it would be expected that those EYH Alumnae responding would report having become scientists. And while they reported the influences of EYH on their decisions, our interpretation of those influences can not be generalized to the EYH alumnae population. The participants were not randomly selected for participation, they represent only a fraction of EYH alumnae and it is possible that self selection bias created a sample of women who were influenced by EYH and wanted to share that experience with the EYH Network.

An earlier study supported by the National Science Foundation considered outcomes for $7^{\text {th }}$ to $12^{\text {th }}$ grade attendees at six 1981 San Francisco Bay Area EYH conferences ${ }^{21}$. Researchers collected pre and post conference data from girls on the day of the conference. Six months later a stratified random sample $(\mathrm{n}=389)$ received follow up questionnaires. With a response rate of $67 \%$, the 261 follow up surveys were matched with conference day surveys for analysis.

Overall, Davis and Humphreys found that conference participation created an increased interest in nontraditional careers and increased the number of math classes that girls expected to take. Six months later the girls reported taking even more math than they thought they would by the end of the EYH conference. The girls had also taken a number of actions to learn more about nontraditional careers: they talked to parents, worked in science-related jobs and found information at the library. Davis and Humphreys (1985) concluded that these conferences were an effective and inexpensive intervention. Yet, without a comparison sample of girls who did 
not attend EYH, one can not be certain the post-conference actions reported by the girls can be attributed to their EYH participation.

As Davis and Humpreys suggest with their qualitative data, the conference may serve as a significant forum to help girls maintain their interest in math and science and resist the pressures to follow more stereotypically feminine career paths. Students reported that workshop leaders helped "shatter" stereotypes of scientists and helped them "withstand social pressures" (p. 96).

A third study by Tomhave (1990) addressed many sampling issues common to program evaluation studies by taking advantage of quasi experimental design. She compared three groups of girls who were in junior high school in 1982: girls who did not intend to participate in an 1982 EYH conference ("nonintended"), girls who intended to participate and were "present", and girls who intended to participate but were "absent" due to a snowstorm.

As one might expect, the girls who intended to participate in $\mathrm{EYH}$, whether they were present or absent, reported liking math and science more than the girls who never intended to participate. By using the absent girls as a control group, Tomhave was then able to control for any possible effects of this original difference in interest. In other words, the Tomhave study could suggest that it was indeed the EYH program itself, and NOT attendee predisposition to science and math, that changed long-term outcomes. Tomahave also controlled for possible effects of town size and distance, as well as course availability.

Tomhave (1990) found in 1990, eight years after the conference, that those who attended EYH reported taking significantly more years of math classes in high school than either the absent or nonintended groups. In general, girls from all three groups ended up taking more math (specifically trigonometry) than they thought they would in 1982, suggesting that junior high girls probably do not understand high school curriculum well enough to predict their own behavior with accuracy. Yet in 1990, EYH attendees were more likely to have taken Trigonometry than the absent or nonintended groups.

While those who attended EYH took more years of science than the nonintended group, this difference could not be attributed with certainty to EYH attendance: There was no significant difference in the years of science taken between EYH present and absent groups. Looking specifically at Physics, 50\% of EYH attendees enrolled compared to 35\% and 30\% of absent and nonintended girls respectively (p. 27). While Tomhave reports that these differences were not statistically significant $(\mathrm{p}<.094)$, the results substantively suggest that EYH may have affected upper level science taking ${ }^{22}$.

By 1990, past EYH participants were the most likely group to retain plans for earning a professional or doctoral degree. Yet plans for earning an advanced degree had decreased in all groups: women in all three groups were less likely in 1990 than they were in 1982 to express plans for an advanced degree. This would indicate that EYH had some effect on advanced degree plans of its participants. Still, very few women in any of the groups had chosen career paths that required "much" math and science and there were no differences in career types of the groups $^{22}$. 
The patterns reported above would indicate that EYH influences high school course taking and subsequent levels of higher education; yet retained interest in math and science careers may require additional interventions. By 1990, all three groups of women had developed similar levels of interest in math and science ${ }^{22}$.

\section{Purpose of This Study}

The following reports a portion of a longitudinal evaluation of the 2001 and 2003 Humboldt EYH conference for middle school girls and contributes to this small literature considering longterm influences of EYH participation. This evaluation gives special attention to EYH Native American girls. Within the Humboldt County public school system ( $\mathrm{K}-12$ th grade), $12 \%$ of the students were Native American $^{23}$. At the Spring 2003 Humboldt EYH Conference, $18 \%$ of attendees identified as Native American ${ }^{18}$. This was the largest ethnic minority represented at the conference that year.

This study uses qualitative research methods and is based on semistructured interviews with 22 high school girls who had participated while in middle school in a 2001 or 2003 Humboldt State University Expanding Your Horizons Conference. (Non-EYH attendees were also interviewed, but those interviews have not yet been analyzed.) Between May 2005 and May 2006 nine of the girls completed individual interviews and 13 took part in 5 small group interviews. At the time of the interviews, 2 to 5 years had passed since they attended EYH.

This study was conducted at a time when the Humboldt AAUW branch was considering the sponsorship of more intensive programs such as "Tech Trek" in lieu of EYH. Expanding Your Horizons conferences are time and labor intensive, but serve many girls, involving more than 200 volunteers for a relatively low cost of $\$ 20$ per girl. More intensive programs such as the popular "Tech Trek" cost approximately $\$ 500$ per girl. High costs combined with travel distances for girls living in remote areas of Northern California would likely mean fewer girls would be reached by such a program. Still, the question remains as to whether EYH accomplishes program goals for STEM participation or whether more intensive programs such as Tech Trek would be better investments.

\section{Methods}

\section{Research Team}

Ten university students (4 graduate and 6 undergraduate) and two high school girls contributed to the design and implementation of this research study. All the research assistants were in their twenties and could have "passed" as high school students. By choosing an all-women research team women and girls had the opportunity to do the social science of this project. In addition, it was important that data collection be conducted by younger women.

Much of the literature on children as research participants takes up the issue of power differences between the researcher and the participant. The adult/child relationship implicitly contains a 
power differential given the structure of our society. This relationship coupled with ethnic differences and the power differences in the researcher/participant relationship may impede the interview conversation.

Many strategies have been suggested to address the power issues around teen interviewing. Eder and Fingerson (2002) discuss the advantages of small groups of peers, teens as facilitator or cofacilitator in the interview process, and the use of interview staff closer in age to the participants $^{24}$. Similarly, same ethnicity and gender interviewing can be helpful in talking with girls of color ${ }^{25,26}$. In general, other researchers have addressed power issues through a feminist approach to interviewing that rests on a more interactive style that incorporates interviewer selfdisclosure ${ }^{27.28,29}$.

We considered all these suggestions and scheduled small group discussions when possible. We conducted one-to-one interviews when there was only one student in a racial group, if the other students who were scheduled for a focus group did not show up, or when other scheduling demands required it.

Two female faculty members, one from Sociology and one from Engineering, were also involved in the project. Eschenbach, the engineer, is the Director of the Humboldt State University Expanding Your Horizons Conference. She contributed by providing past conference records, keeping abreast of changes in the field, and presenting workshops related to our study. She was also a resource on the literature related to girls and women's participation in science, technology, math and engineering (STEM) and related fields. As the team's lead sociologist and research director, Virnoche coordinated the overall project and an ultimately responsible for the decisions that were made.

For the most part, the research team agreed that the interviews themselves went well. Most of the girls seemed very comfortable sharing their high school experiences. They were often animated in the description of their experiences. Jokes and laughter were common. There were, of course, some girls who were quieter than others and required the facilitator to work harder to draw them into the discussion. The team was coached in feminist methodology that encourages sharing. So research team members shared their own stories of high school math and science and college as they encouraged participants to retain their interest.

\section{Sampling Method}

We analyzed the elementary school names of the 2001 and 2003 EYH participants and anticipated the high schools that these girls were most likely to attend. After sorting the lists based on likely high school attendance, we chose two regional high schools that were likely to enroll the greatest number of EYH girls and one high school that enrolled both a large percentage of EYH girls and overall had a high enrollment of Native American Students. High school staff confirmed enrollment of the girls.

Study information packets were delivered to the girls through our high school contacts at Big Bear and Bayview High Schools and through U.S. mail for Oceanview girls who came late into 
the study. Each envelope contained a cover letter from the school contact (Appendix A) two copies of a letter to parents or guardians that doubled as a consent form (Appendix B) and a flyer designed to catch the girl's attention (Appendix C). The flyer highlighted the incentives for participation including free food and drinks, a party, and a raffle for a computer and other prizes. Big Bear and Bayview girls were asked to return their consent forms to the school office. We provided Oceanview girls with stamped return envelopes. Bayview and Big Bear received two to three solicitations that in many cases involved personal encouragement from school staff.

\section{Sample Description}

The 22 girls attended one of three high schools in Northern California: Oceanview, Bayview and Big Bear. Oceanview and Bayview were fairly large schools for this area of the state enrolling 800-1800 students. These schools were predominantly white. Big Bear was a smaller school enrolling less than 300 students and served a majority of Native American students.

Three of the girls who participated were Native American, one girl identified as Native American and Mexican American, and the other 18 girls were white. The girls came from working class and professional families. While most of the participants reported attending one of the 2001 or 2003 conferences, several girls reported attending both. Table 1 summarizes the participants' ethnicity and the interviews styles.

Table 1: Race/Ethnicity of Participants

\begin{tabular}{|c|c|c|}
\hline & Past EYH Participants & Comments \\
\hline White & $\begin{array}{l}82 \% \\
(18)\end{array}$ & $\begin{array}{l}\text { (7 individual interviews) } \\
\text { (11 in small group) }\end{array}$ \\
\hline $\begin{array}{l}\text { Native } \\
\text { American }\end{array}$ & $\begin{array}{l}14 \% \\
(3)\end{array}$ & $\begin{array}{l}\text { ( } 1 \text { individual interviews) } \\
\text { ( } 2 \text { in small group) }\end{array}$ \\
\hline Multiracial & $\begin{array}{l}5 \% \\
(1)\end{array}$ & (Native American/Mexican American) \\
\hline Total & $\begin{array}{l}100 \% \\
(22)\end{array}$ & \\
\hline Response Rate: & $22 \%$ & $\begin{array}{l}\text { Consent Forms Received: } 25 \\
\text { Total Packets Mailed: } 101\end{array}$ \\
\hline
\end{tabular}

Ultimately, 22\% of the 101 past EYH participants that we contacted turned in permission forms and followed through with an interview. While our response rate for past EYH participants (22\%) was not as high as we would have liked, it is respectable given the warnings we received about the challenges outsiders would face recruiting high school girls for interviews on math and science. EYH registration materials did not collect ethnicity information linked to names for the 2001 and 2003 conferences attendees. And due to educational privacy restrictions, the high school contacts could not release information on any girls on our EYH participant lists. Therefore, we can not report whether the response rates of girls of color were any different than those of white girls. However, EYH girls were more than twice as likely to participate in the study as compared to a sample of girls from the larger study who had never attended an EYH. 
(Those results are not reported here, as comparative analysis between EYH and Non EYH girls is not yet complete).

\section{Small Group and Individual Interviews}

Graduate Research Assistants sorted the parental consent forms by school, EYH status and ethnicity and organized groups accordingly. For the small group interviews, the graduate research assistants contacted each girl by phone, spoke to her briefly about the study, and asked her to participate in a group discussion or a one-to-one interview. A series of phone calls were usually needed to coordinate a meeting time. All girls received a follow-up reminder call 1-2 days before the interview.

These interviews were in most cases conducted after school in available classrooms or other meetings spaces. In all group discussions, girls read and signed assent forms that stated they would keep confidential the discussions of their peers (Appendix D). In a few cases, we did oneto-one interviews at a quiet local restaurant.

The undergraduate researchers conducted the phone interviews later in the project. The team gathered in the early evenings and called lists of girls. They either conducted the interview immediately or tried to schedule another time for the call. They improvised their introductions based on a general script encouraging the high school girls to find a quiet place in the home where she could talk openly and without distractions. They used structured interview guides that Virnoche adjusted based on data from earlier small group interviews. Digital audio recordings of all interviews were captured, transcribed and entered into NVivo for analysis. In most cases the interviewer transcribed her own interviews.

\section{Data Analysis}

The digital recordings of interviews were downloaded and burned to compact discs. Research Assistants used Express Scribe, a freeware product, to play and transcribe the recordings into word processing files. The transcriptions were then imported into Nvivo, a qualitative data analysis program.

NVivo is a qualitative data analysis software program for researchers who need to organize and analyze many interviews, field notes and other types of non-nonumeric data that are lengthy and nuanced. The program allows the same passage of text to be coded as representing multiple themes or theoretical ideas. The program will interface with spreadsheet programs and higher powered social science quantitative data analysis programs such as SPSS. These interfaces allow researchers to link quantitative and qualitative data sorting "chunks" of narrative that have been coded around themes and subthemes by categories such as race and class that may be more easily converted to numeric data. For those qualitative studies that rely on random selection, the integration of these techniques of analysis allows for nuanced theoretical statements coupled with statistically supported statements relying on probability theory. 
In the case of research for this paper, these techniques allowed the researcher to quickly compare and contrast narratives of Native American girls around a particular theme with those of other white girls in the study. While the programs integrate tools that assist the researcher in searching for and coding the data around themes, much of the work still requires time-tested techniques of repeated reading of narratives while considering both overt and underlying meaning.

During the course of interviews, the research team discussed the themes that they were hearing. Virnoche kept notes and also began to review transcripts. Virnoche developed an initial coding scheme based on discussions and a quick read through the transcripts. A graduate research assistant and Virnoche used this coding scheme to systematically read through the transcripts and code passages accordingly. In this process, we noted themes that needed to be added to the coding scheme and discussed their organization. Interviews were also coded to allow for analysis based on demographic information.

\section{Limitations and Challenges}

The recruitment barriers that we faced were complicated by privacy and student data concerns and policies. Working through school principals in two school cases, we were linked with school counselors who were our main contacts for the project. On directions from the principals, school staff members were the only ones allowed to see student names and distribute information to the girls. Since we could not contact the girls directly at these schools, solicitation phone calls were impossible. Follow up mailings were taxing on already overstretched school staff. And although we had good working relationships with the staff, we all felt a bit hesitant each time we had to contact school staff for yet more help.

At the largest school, we paid one administrative staff member at an hourly rate to provide clerical help to the counselor with whom we were working. The clerical staff member requested a fairly high hourly rate and her services became very costly. Yet we were in a bind trying to reach the girls. To her credit, she did come in early and stay late to get the work done. She summoned each of the selected girls into the office, explained the study, and encouraged each to participate. At the smaller school, we were able to offer the counselor assigned to work with us a small stipend for her time. She seemed happy with the stipend. On top of sending out two mailings, she also told us that she talked in person to many of the girls about participating in the study.

\section{Results}

\section{Deciding to Attend the Conference}

Almost all the girls who remembered the conference recalled that teachers, counselors or parents were the catalysts that got them to the EYH conference. They went because they were interested, and/or they wanted to escape their rural communities and/or they wanted to join in with friends. Strikingly absent from the narratives of Native American girls, as well as the white girls from the predominantly Native American school, was any discussion of parent involvement. 


\section{Experiencing STEM through EYH}

Most of the girls held detailed memories of the conferences, while a couple had foggy memories and one girl could not recollect attending at all. Particularly for the girls from Big Bear High School, their memories of EYH had become interwoven with many other visits to Humboldt State University. Collectively they constructed and reconstructed the "right memory" correcting one another so as to focus everyone's memories on the EYH conference. Most girls relayed excitement as they recalled the hands-on workshops and interactions with volunteers. Others discussed a sense of empowerment being surrounded by so many other girls and women who were interested science and math. A couple girls were disappointed as workshops simply replicated negative high school experiences of math.

Most of the girls retained detailed and pleasant memories two to three years after participating in EYH. When asked to recall their activities, many took the interviewer step by step through the day, as well as the particular workshops that she had attended.

Cheryl had just completed her sophomore year at Oceanview High school when we interviewed her. Cheryl was one of the four EYH alumnae who participated who identified as Native American. Her father had been a wildlife biologist and was significant force in shaping her career interests. Cheryl wanted to be a veterinarian or something like that. She described her two years of EYH hands-on activities with enthusiasm:

She also told us that she remembers following up on her EYH experience with additional web research of her own. She was particularly intrigued by the astronaut who spoke and she was encouraged to check out satellites that orbited the earth.

Several of the girls discussed feelings of empowerment as they entered a gymnasium and were surrounded by other girls and women who they assumed liked and/or were good at math and science. Even as they relayed the experience now as a memory, they still thought it was very cool. Now in high school, the girls who remained interested in math and science reported high level math courses with few girls compared to boys.

The two Native American girls in the Big Bear group offered the clearest memory of EYH. While the other girls were still trying to figure out which of their experiences had been $\mathrm{EYH}$, the two Native American girls clearly co-constructed their EYH day. They described the campus, the gym and science fair booths and the workshops they attended. They reported both attending a workshop on where they were given a piece of paper and they "learned math stuff." Both agreed that it felt "like school" and was not so fun.

We never learned the career paths of these girls as they left the interview quickly. When pressed about her current school experience as she packed her bags, one girl tearfully suggested that she could not get the types of more challenging classes that she needed and was going to have to transfer to a different high school. She clearly had plans for higher education and was worried about her work at Big Bear. 


\section{Shining Lights in the STEM Career Black Box-EYH Experiences vs. Popular Culture}

For the most part, the girls relayed limited and shallow understandings of math and science professions. They constructed their images from observations of common service providers such as doctors, discussions with relatives who worked in STEM fields and popular culture. Because of these limited avenues for learning about professions, girls told us that it had been important to them to talk with EYH volunteers about their jobs and how they got there. Workshops and informal discussions with conference volunteers working or studying in STEM fields provided rare glimpses into professional worlds that remained a black box for most of the girls. While a few girls credited EYH with their current STEM career path, others suggested that early postEYH enthusiasm for STEM had waned.

Most of the girls looked to teachers and professionals such as doctors as the only real people that they knew who worked in STEM fields. One girl from Big Bear high school talked about a relative who was an "engineer." Her face crinkled up with disapproval as she considered this occupation for herself. For her, an engineer was a construction worker like her Uncle. She associated engineering with being dirty and scruffy and it did not fit the image she had for herself. This image remained with her despite the fact that she had encountered at least one woman who was an engineer and directed the EYH conference.

Another white girl from Oceanview discussed a cousin who was a recent Cal Poly engineer graduate. "She's a pretty, blond cheerleader and she's really smart. She lives in an apartment in San Francisco. As soon as she graduated CalPoly they gave her fifteen thousand dollars to move to San Francisco if she'd do this job. She builds buildings. She says, "This will work" and will do all the math for it and then goes out and helps them build it. I think that's cool."

For a number of girls, the EYH experience "sparked" their interest in fields they knew little about and had never considered. Cheryl's experience with the Vet encouraged thinking about her own career aspirations and gave her a new perspective on what being a vet could really be like:

I met a traveling vet who went around in her van all day. That was cool and shut my fear (of an office job) out. She showed us how to do the stitch on the stuffed cat and gave us the needle. She talked about what she did instead of being a regular vet. She talked about the dogs she'd saved. I never thought a vet could go around in a van. That was way out there and I'd never thought about it. I knew there were wildlife parks but I never thought there would be a vet like that.

Cheryl's story of a peek into "a day in the life of a traveling vet" is an example of the significance of shared career narratives and paths at EYH conferences. She had never considered that a veterinarian could work outside a typical medical office. For her, the career narrative of the traveling vet opened new ways of thinking about future study and career paths.

Cheryl, as a Native American raised mostly among white people, saw images of white men when she thought about math and science. She had had only one woman as a science teacher. She 
noted that of course she knew women could be mathematicians and scientists, but EYH helped that image be more real.

It reminded me of it...I knew, but it started to get into my subconscious a little more. I could get more actual pictures of a female scientist from that...

For Cheryl, EYH served to reinforce her interests in science.

In addition to new career ideas, girls also discussed the significance of EYH for reinforcing existing interests in various careers. Two white girls from Bayview were already on a track for advanced science and math course taking when they attended EYH. Both were hoping to get into top universities and were doing everything they could to make that happen. They both liked math more than science, and agreed it was just fun but that you couldn't really use math to "do" anything unless it was combined with science. While Bianca had an already established theatre career and planned to continue that pursuit into college - hopefully at NYU, she planned to minor in math "for fun."

Rachael was most interested in Astronomy, though she continued to change her mind. She recalled the influences of EYH on her career aspirations:

I think the most important thing was that it sparked my interest more in astronomy. That's where I heard what engineering was and what it means. I'm still kind of interested in that. I don't know if I want to be an engineer, but that field and that research was introduced.

Rachael had also since had an opportunity to visit an astronomy lab at UC Davis that was very interesting for her. As noted above, she and Bianca were advanced students and very goal oriented. Both their parents were heavily involved in their decision making and they noted the great deal of support they received from them. Rachael's mother had attended EYH with her.

Kelly was a sophomore whose interests in nursing were sparked through EYH:

We made splints for our fingers...with wax and hot water. We carried them around all day and thought they were cool. I made two of them. I remember that so well. I think there were three women that did it and they were a little bit older, nursing assistants...or nurses. All three of them were really funny. That was fun. That's the only thing that sticks in my head from EYH. It was so cool....

Mindy's interest was sparked in dentistry when she attended EYH. In both 2001 and 2003 she attended dentistry workshops and really enjoyed making molds. Even though she's been discouraged from studying dentistry by those who think it's "gross." Another person suggested that maybe she could instead by a dental hygienist. Mindy still likes the idea of being a dentist:

I never hated going to the dentist. My mom said when I was two I would just sit there. I don't think it's all that gross. When I went to EYH, which I did for two years, and the lady remembered me. She said, "You're the one who had the really 
good molds last time." Yeah, that was me. The way everything worked....it just seemed cool and that you would learn something new all the time.... I'm also a perfectionist and when we had the little molds (at EYH) I tried to get it perfectly flat and she said, "It's o.k., it can be a little bit off." I said, "No, it can't. It has to look good." We had to use wax to mold a tooth because there was a missing tooth and I molded the tooth and it looked identical to the other one and she said, "Wow, you did an awesome job."

Her mom supports her interest and is trying to arrange for Mindy to spend some time working in a dental office.

One of the white girls from the Big Bear group discussed the influence of EYH on her career planning. She thought she wanted to be a marine biologist and she got to learn more about marine biology and oceanography. While she now wanted to be a psychologist, she felt that the people she talked with at EYH were helpful to her process of thinking about career.

Still, some girls told us that workshop leaders shared little if anything about their own professional trajectories. Busied by the task of workshop activities, the leaders missed the opportunity to share their personal narrative with the girls.

A number of girls reported a dissipating effect of EYH on career interests as high school experiences took over. Heidi was a white senior from Oceanview whose parents had completed some college. When she began her interview, she had given up thinking about herself as a scientist despite five years of math and four years of high school science.

I remember back then I was really interested in (science) and I thought I might want to be a doctor or a scientist. For a while I wanted to do genetics research. I think high school changed that for me since I thought I wasn't as good at science or math. When you think you're not good in something, you can't really have a career in it.

When pressed by the interviewer on her self-evaluation of not being "good enough," Heidi reflected self-consciously on how she came to that conclusion. For her, it was clear that if others were finishing assignments faster than her with fewer questions, then the field was not a good choice for her. Heidi felt there should be a synergy between what came easy to a person and their chosen profession.

Yet Heidi was not a bad student. She was just not as good as others. She been accepted to Dartmouth and planned to begin study there in Fall 2006. Her high school math and science classes had taught Heidi that math and science were for people that liked to problem solve for one right answer: "There was always only one answer and you either got it wrong or right." For Heidi, people like her, who liked to look at problems and ideas from multiple perspectives, well they were just better suited for majors like comparative literature.

Denise was a Bayview junior who identifies as white and then Cuban. She was awed by math and science at the time of the conference. She was doing well in both and her science teacher 
encouraged her to attend with her mom. After the conference, she thought she would become a marine biologist. Later her high school science teacher told her that it would take a lot of math to be a marine biologist. She was good at math and science scoring in the $98^{\text {th }}$ percentile on her STAR test and is taking 4 years of college prep or advanced placement math \& science. Yet math bores her. So her latest plans involve becoming a high school English teacher or a social worker and helping kids.

So the effects of EYH had worn off for Heidi, Denise and others. Denise could not imagine continuing with more math to reach her career goals. Heidi no longer thought genetics was a good choice for her. Yet by the end of the interview, perhaps because of the interviewer questioning of her reasoning, or perhaps because of recollection of early experiences of science, Heidi defiantly stated that she would give science another try at Dartmouth.

"I think in college I will give math and science another chance. I can't let what happened in high school dictate everything else," she stated. To that extent, the interview itself may have been an additional intervention that helped girls like Heidi reconsider a long lost love with math and science.

For many girls, television and movies remained a primary sources of information on careers. EYH organizers understand this affinity, and workshops on forensics and other crime solving topics remain popular offerings for middle school EYH attendees. Now in high school, the past EYH participants shared narratives that relayed an ongoing seduction by Hollywood.

Crime solving and law enforcement series flood the selection of television dramas. So it is no surprise that images of science professions were sometimes synonymous with crime solving. The series construct exciting images of crime investigators, police, lawyers and other related professionals. Computer scientists if they are present appear briefly to support field officers as they quickly press buttons on the keyboard and reveal data that solves mysteries. Engineers, physical scientists, mathematicians and the like are all but absent from these popular evening dramas.

Holly, a white junior from Bayview whose parents both held college degrees recalled her interests in forensics until she experienced the real thing. After being turned on by "CSI", she job shadowed at the coroner's office but was turned off by the reality of the work:

I've been watching CSI for quite a few years. And I wanted to become someone who works in the coroner's field until I went on middle school job shadow and was kind of turned off by the whole idea. It's just as gnarly as TV but not as played up. It's kind of plain in a way and kind of smells weird. It wasn't my ideal job.

Lynn, a white freshman from Oceanview talked about movies like Miss Congeniality and the TV series "Walker Texas Ranger" sparking her interest in FBI and DEA work. She wanted to be out in the field "arresting the worst criminals." After a job shadow with a street job, she was assured that she didn't need to go to college to be a cop in the field. He connected college with being a lieutenant which meant having a desk job. 
Jennifer, a white junior knows that there are problems with the images of scientists on TV. "They're shy and nerdy." Yet in real life she observes that "they seem like regular people." When I watch TV, I see more women, but at Bayside High, the science department is full of men. We have one female teacher and she's new. Maybe I don't want to say it's being dominated by males...maybe I just don't like saying that. I don't want to say it.

\section{On Message: Take More Math and Science....}

The take home message of EYH is "Take more math and science in high school so you have more options later in life." While some of the girls said EYH had little affect on their course taking and others were uncertain, many felt that it helped them to have that reinforcement of interests and/or encouraged them to take more or particular types of math and science that they would not have otherwise taken.

For many girls who attended EYH they already had an interest in science and math: Their interest drew them to the conference. So the conference served to reinforce that interest and course taking related plans. According to one white Oceanview girl who attended EYH as a seventh grader:

I remember thinking it was really cool and I was really excited. I don't know if it changed anything but it didn't hurt anything. It was just further proof that science is awesome. It was really fun and made me happy about it (science). I didn't say it sucked afterwards.

For another white Oceanview girl, the workshops helped her understand what high school science would be like and get excited about it:

I remember thinking, "I get to take science classes in high school and that's going to be cool." And I was in the science room and thinking about labs and stuff. I think it gave me a new look at science. How it would feel to take the classes in high school.

For Terri, an Oceanview junior, she recalled perfectly the message of the conference. She also drew clear connections between that conference experience and her experiences in math and science afterwards. It not only influenced her course taking, but the degree of attention she paid particularly within her science classes:

It made me really interested in science...so I really paid attention, especially in eighth grade science. It was really hard and I had Mr. Hall who was a very strict teacher but it made me...in both seventh and eighth grade science, made me want to learn as much as I could and get good grade because they pushed learning math and science to get into college (the conference). They said, "Science and math is super important. You can use it in everyday life and whatever career." And they 
had so many different careers, and they said, "Whatever you decide to do, you're going to be needing science and math."

Teri maintained this frame despite even recent counter arguments from her own mother who had had a poor experience in the Biology:

My mom asked me the other day why I was taking Biology and I said, "You can use Bio in whatever you do." And she said, "I'm sorry but I haven't used Biology since I got out of the class in high school." Whatever. She also had a very bad experience when she was in Biology in high school and she came into the class and there was a male teacher. And he said, "I know that the boys are going to do better than the girls in this class because guys are better at science than girls are." So my mom stood up and said, "Then I'm not in this class" and got a different Biology teacher.

Other girls were very sure about the influence on their course taking. One girl who got interested in dentistry after the conference said it influenced her science decisions but not her math:

When I picked my classes I was thinking about what would be better if I was going into dentistry. And I knew I would take Bio and Chem. I would rather take Bio because it was easier and I was better at it. I don't know...the body...the mouth. ... It didn't really influence my math classes because I was good at math and I want to know as much as I can because it will be easy for me. And you can use math in whatever you do so it would be easy just to get ahead.

\section{Recommendations for Future EYH Outreach Events}

After reviewing the girls' responses, the following recommendations can be made to maintain and increase the effectiveness of future EYH conferences.

1. Find engaged teachers and counselors to promote involvement of students from groups that may not have as involved or college savvy parents. Girls from lower socioeconomic backgrounds will be less likely to have other support networks to facilitate their conference attendance. These same groups may need transportation assistance and much encouragement and support at the school to attend. When possible, build teacher time into budgets to support involved teachers and counselors. Often teachers are as or more interested in finding time for the many additional demands on their time rather than financial payment for their help (Virnoche \& Lessum 2006).

2. When working with workshop leaders, emphasize the importance that the workshop be a hands-on experience and not "just like school". As much as possible, use evaluations to identify future workshop leaders that have strong hands-on activities.

3. If possible, provide the girls opportunities to identify and tell stories of women who "have it all." (beauty, popularity, intelligence and accomplishment). Workshop leaders 
and plenary presenters can serve this role. Girls at this age are very conscious of appearance and popularity. Self worth for girls revolves around physical characteristics. (Of course beauty is in the eye of the beholder!)

4. Workshop leaders should be sure to take the time to explain their career paths. Girls do not have much access to these paths otherwise, as they are not presented in popular culture.

5. When possible, workshop leaders should present problem solving and experimental design from multiple perspectives, so that it becomes clearer that there is not "just one answer". Some girls perceive math and science as not for them because they believe there is only one solution to math and science problems. .

6. It is important to have multiple interventions to counteract the images of STEM areas the girls find in popular culture because the impact of the EYH conference fades over time. (The girls usually do not identify with these images, as well as they identify with the presenters and other participants at the EYH conferences). Consider offering the conference every year to multiple ages. In addition, consider offering additional opportunities for girls to experience STEM areas.

7. Whenever possible, provide women role models in STEM areas for girls. High schools need to hire women science and math teachers when possible.

8. EYH conferences can offer workshops for parents, teachers and counselors to help them envision a wider possible set of futures for these girls. Parents, teachers and counselors exert a large influence on girls' perceptions of their future options.

\section{Acknowledgements}

This research was funded in part by a Community Action Grant from the American Association of University Women Educational Foundation and matching cash and in-kind grants from the Humboldt State University Foundation and other Humboldt programs and departments.

\section{Bibliography}

1. American Association of University Women Educational Foundation. (1999). Gender Gaps: Where Schools Still Fail our Children. New York: Marlowe.

2. Fennema, E., and Sherman, J. (1978). Sex-related differences in mathematics achievement and related factors: A further study. Journal for Research in Mathematics Education, 9(3), 189-203.

3. James, R.K., and Smith, S. (1985). Alienation of students from science in grades 4-12. Science Education, 69(1), 39-45.

4. White, P.E. (1992). Women and minorities in science and engineering: An update. Washington, D.C.: National Science Foundation.

5. Catsambis, Sophia. (1994). "The Path to Math: Gender and Racial-Ethnic Differences in Mathematics Participation from Middle School to High School”. Sociology of Education. July (67). 199-215. 
6. Becker, J.R. (1981). Differential treatment of females and males in mathematics classes. Journal for Research in Mathematics Education, 12, 40-53.

7. Eccles-Parsons, J. (1984). Sex differences in math participation. In M.L. Maehr and W. Steinkamp (Eds.), Women in Science. Greenwich, Conn: JAI Press.

8. Gilbert, P., and Taylor, S. (1991). Fashioning the feminine: Girls, popular culture and schooling. North Sydney: Allen \& Unwin Pty Ltd.

9. Kahle, J.B. (1990). Real students take chemistry and physics. In K. Tobin, J.B. Kahle, and B.J. Fraser (Eds.), Windows into science classrooms: Problems associated with higher-level cognitive learning. New York, NY: Falmer Press.

10. Wilkinson, L.C., and Marrett, C.B. (Eds.). (1985). Gender influences in classroom interaction. San Diego, CA: Academic Press.

11. Wertheim, M. (1995). Pythagoras' trousers: God, physics, and the gender wars. Toronto: Random House of Canada Ltd.

12. Seymour, Elaine and Hewitt, Nancy. 1997. Talking About Leaving: Why Undergraduates Leave the Sciences. Boulder, CO: Westview Press.

13. American Association of University Women Educational Foundation. (2001). Beyond the Gender Wars: A Conversation about Girls, Boys and Education. Washington, D.C.

14. American Association of University Women Educational Foundation. (2000). Tech-Savvy: Educating Girls in the New Computer Age. Washington, D.C.

15. 2004. Math/Science Network Annual Report 2003-2004. Retrieved January 22, 2006: http://www.expandingyourhorizons.org/AnnualReports/Annual_Reports.html

16. US Census 2000. Retrieved March 6, 2007 http://www.census.gov/main/www/cen2000.html

17. Roberts-Ohr, Stacey and Spencer, Cherrill. 2006. Expanding Your Horizons in Science and Mathematics Conferences: A Retrospective Summary of Conference Data, Evaluations and Statistics. EYH Network. Unpublished Report.

18. Thompson, Leah and Virnoche, Mary. 2003. Expanding Your Horizons: 2003 Conference Evaluation. Humboldt State University, Arcata, CA. Retrieved June 26, 2006: http://www.humboldt.edu/ soc/Expanding\%20Your\% 20Horizons.pdf.

19. Cortez, Lori and Virnoche, Mary. Forthcoming. Expanding Your Horizons: 2005 Conference Evaluation. Humboldt State University, Arcata, CA.

20. Spencer, Cherrill. 2006, June 26. Personal Correspondence.

21. Davis, Barbara Gross and Humphreys, Sheila. 1985. Evaluating Intervention Programs: Applications from Women's Programs in Math and Science. New York: Teachers College Press.

22. Tomhave, Judith Ann. 1990. "The Effects of a Short-Term Intervention Program on Future Participation in Math and Science." M.A. thesis, Department of Psychology, North Dakota State University, Fargo, ND.

23. XYH Office of Education Annual Report 2002-2003

24. Eder, Donna and Fingerson, Laura. 2002. "Interviewing Children and Adolescents." Pp. 181-201 in Handbook of Interview Research, edited by Jaber F. Gubrium and James A. Holstein. Thousand Oaks, CA: Sage.

25. Dunbar Jr., Christopher, Rodriguez, Dalia, and Parker, Laurence. 2002. "Race, Subjectivity, and the Interview Process." Pp. 279-298 in Handbook of Interview Research, edited by Jaber F. Gubrium and James A. Holstein. Thousand Oaks, CA: Sage.

26. Ryen, Anne. 2002. "Cross-Cultural Interviewing." Pp. 335-354 in Handbook of Interview Research, edited by Jaber F. Gubrium and James A. Holstein. Thousand Oaks, CA: Sage.

27. Harding, Sandra Ed. 1987. Feminism and Methodology. Indianapolis: Indiana University Press.

28. Nielsen, Joyce McCarl ed. 1990. Feminist Researh Methods: Exemplary Readings in the Social Sciences. Boulder, CO: Westview Press.

29. Reinharz, Shulamit. 1992. Feminist Methods in Social Research. New York: Oxford University Press. 


\section{Appendix A Cover Letter from High School Staff}

March 8, 2004

Dear Parent or Guardian:

Thank you for taking time to review the "Girls in Math and Science" study information included with my letter. I have been working with Professor Virnoche, a Sociologist at Humboldt State University, to better understand how local high school girls are making decisions about their math and science education and future careers.

Girls now take as many high school science classes as do boys (though fewer girls than boys take physics), and girls' achievement levels are roughly the same as boys. Yet important disparities in aspirations and career paths remain. (American Association of University Women)

Your daughter was selected to participate in this study because she participated within the last five years in an Expanding Your Horizons Conference at Humboldt State University. These conferences are part of a national network to encourage girls to take more math and science in high school. Girls participating in the study will be asked to give phone interviews. Some will participate in group discussions about science and math course and career interests.

As indicated in the enclosed materials, your daughter's privacy will be protected: her name will not be included in any reports produced by the project.

We want to make sure our girls are prepared to go on in any field that they choose. Please help us understand the issues better and return the materials provided.

Sincerely,

School Counselor Name 


\title{
Appendix B Researchers' Letter to Parents or Guardian
}

\author{
Original sent on letterhead and fitted to one page
}

March 2, 2005

Dear Parent or Guardian:

Your daughter is invited to participate in a study looking at how girls at (School Names) High Schools are making decisions regarding math and science course enrollment and career interests. If you give permission for your daughter to participate, she will be asked to participate in a phone survey and may also be invited to participate in a 1-2 hour small group discussion about course and career decisionmaking.

Participating girls and their parents or guardians will be invited to an ice cream party at Humboldt State University. The names of girls will also be entered into a raffle for a new computer, as well as books, gift certificates, science kits and more. Free bus transportation between (School Name) and HSU will be provided. In addition to the fun around the ice cream party, your daughter may find it interesting to participate in a study that has national attention and provides the opportunity for her to reflect on her interests and actions around math and science.

Even though girls perform as well as boys in science and math, they lose interest in these areas beginning in middle school. Girls tend to take less math and science courses in high school making it more difficult and less likely that they pursue advanced science and math training and career paths. There have been national efforts to reverse this trend including Humboldt State University's conference for middle school girls, Expanding Your Horizons (EHY), aimed at increasing High School math and science course enrollment. Some of the girls asked to participate in this study have attended past EYH conferences.

If you give permission for your daughter to participate, you also have the right to withdraw your consent at any time. Your daughter may discontinue participation at any time and she also has the right to refuse to answer any question. Your daughter's privacy will be maintained in all published and written materials resulting from this study. Her real name will not be used in any written materials generated from discussion group audio recordings and surveys. Audio recordings will be destroyed at the close of the project. Any records that could link your daughter's identity with the information she provides for the study will be kept in a secure location.

This project is partially funded by a National Community Action Grant from the American Association of University Women (AAUW). The study is directed by Dr. Mary Virnoche and Dr. Beth Eschenbach at Humboldt State University. If you have any questions or concerns, please contact Mary at by phone at (707) 826-4569 or by email at Mary.Virnoche@Humboldt.edu. You may also contact confidentially Dr. Donna Schaefer, Dean of Research and Graduate Studies at (777) 888-3333

Donna.Schaefer@Humboldt.edu. You will find more information about this study on the Internet: http://www.Humboldt.edu/ soc/eyh.htm

Sincerely,

Mary E. Virnoche

Assistant Professor

Coordinator of Practicing Sociology MA

Please keep one copy of this letter and return a signed copy to your school counselor,(Name).
Beth Eschenbach

Professor and Chair

Engineering 


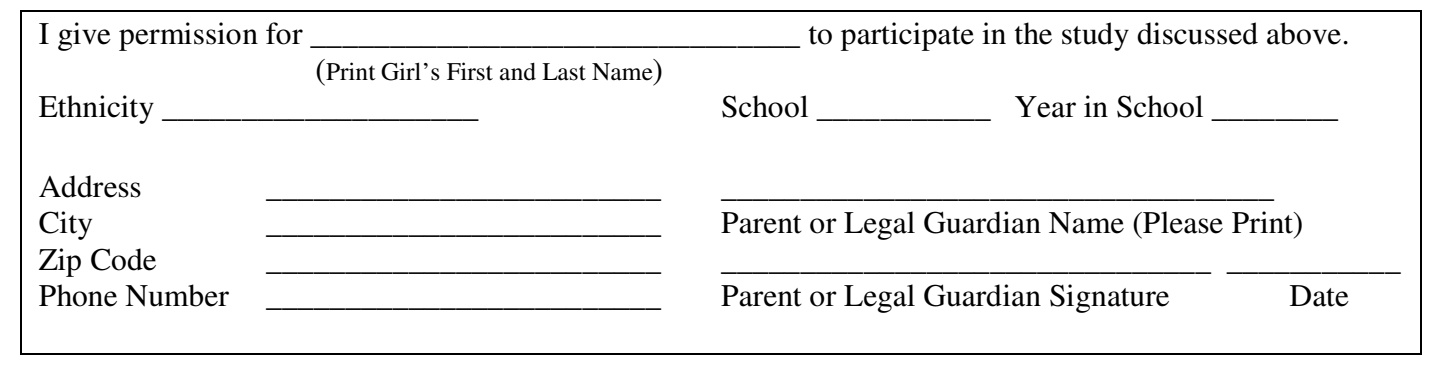


Appendix C Flyer Targeted to Girls

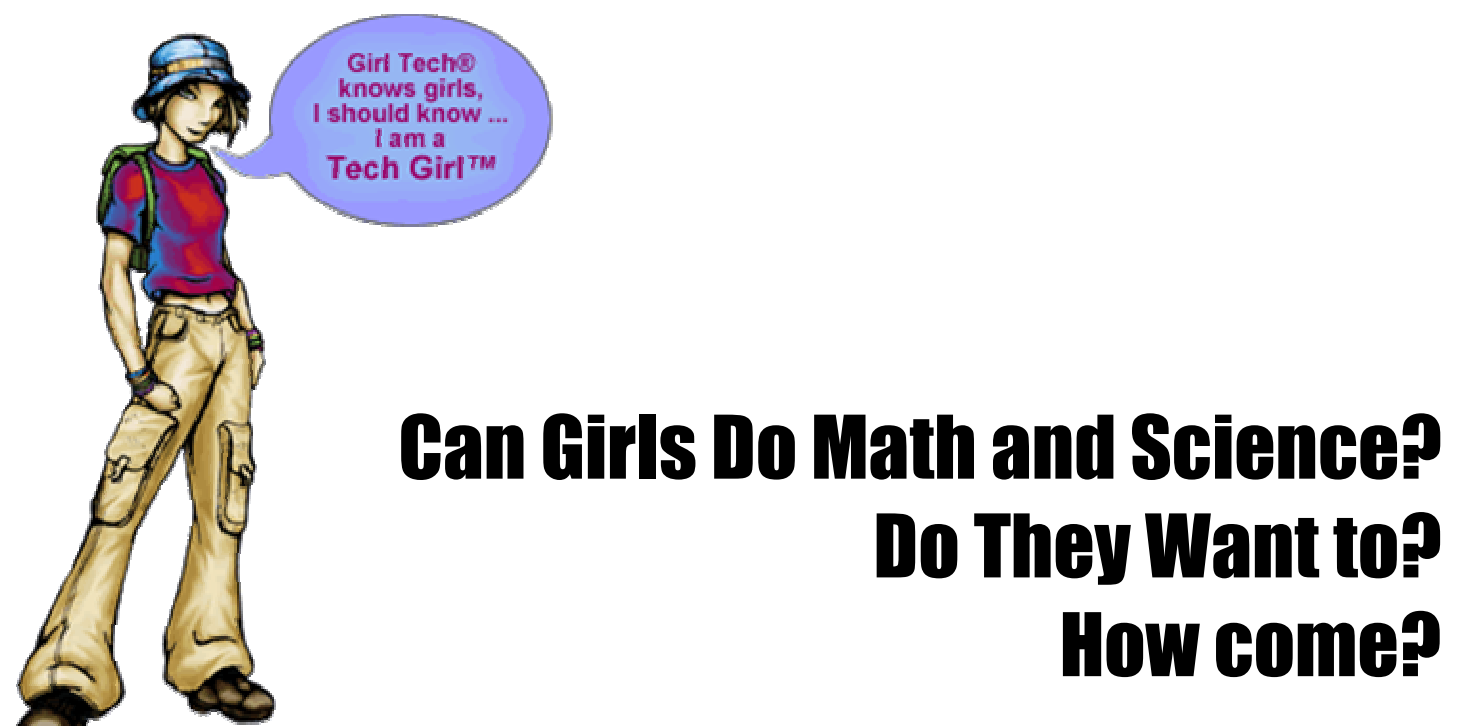

We want to hear what 300 girls from (School Names) Schools have to say about these and other related questions.

Be one of those girls!!

\section{What Do I Have to Do?}

A short phone interview

Maybe a small group discussion with other girls

\section{What Do I Get?}

- A free lunch or dinner (for those participating in group discussions)

- A chance to win a computer, books and other prizes

- An invitation to attend a party at Humboldt for girls participating in the study

- An opportunity to contribute to a study with national attention

\section{How Can I Be Sure I am Included?}

Have your parent or guardian complete the attached permission slip and return it to your school office (School Staff Name's mailbox).

Questions: Contact Mary.Virnoche@Humboldt.edu 888-4444 


\section{Appendix D Assent Form}

\section{AGREEMENT TO PARTICIPATE}

\section{Girls and Decisions about High School Classes \& Careers}

You are asked to participate in a 1-2 hour small group discussion about the high school classes you take and your career interests. Many other girls at (School Names) High Schools will participate in this study.

If you agree to participate, you will be invited to an ice cream party at Humboldt State University and entered into a raffle for a new computer, as well as books, gift certificates, science kits and more.

Please know your participation is voluntary. You do not have to answer all the questions and you can leave the discussion at any time. Your real name will not be used in reports that are written. And the group audio recordings will be destroyed after we type them up.

This study is partially funded by the American Association of University Women (AAUW). If you have any questions now or later about this project, you can contact Mary Virnoche at (707) 826-4569 or Mary.Virnoche@Humboldt.edu. Mary teaches Sociology at Humboldt.

I have read the above and agree to participate in this study.

Student Name

Student Signature 